\title{
EFFECT OF LOCAL MATE COMPETITION ON FIG WASP SEX RATIOS
}

\author{
PEREIRA, R. A. S. ${ }^{1}$ and PRADO, A. P. ${ }^{2}$ \\ ${ }^{1}$ Departamento de Biologia, FFCLRP, USP, CEP 14040-901, Ribeirão Preto, SP, Brazil \\ ${ }^{2}$ Departamento de Parasitologia, Unicamp, C. P. 6109, CEP 13083-970, Campinas, SP, Brazil \\ Correspondence to: Rodrigo A. Santinelo Pereira, Depto de Biologia, FFCLRP, USP, Av. Bandeirantes, 3900 , \\ CEP 14040-901, Ribeirão Preto, SP, Brazil, e-mail: raspereira@yahoo.com.br \\ Received March 8, 2004 - Accepted January 26, 2005 - Distributed May 31, 2006
}

(With 3 figures)

\begin{abstract}
In fig wasps, mating takes place among the offspring of one or a few foundress mothers inside the fig from which mated females disperse to found new broods. Under these conditions, related males will compete with each other for mating and several studies have shown female bias in brood sex ratios as a response to Local Mate Competition (LMC). Studying Pegoscapus tonduzi which pollinates Ficus citrifolia in Brazil, we analysed the effect of LMC (number of foundresses) on the sex ratio of the offspring of pollinating wasps. The relationship between the foundress number and brood sex ratio qualitatively followed the theory, however the empirical sex ratio was more female biased than expected from theoretical values. The model for an optimal sex ratio considers that each foundress wasp contributes the same number of eggs to be bred and that the violation of this assumption may explain the lack of adjustment in relation to the theory.
\end{abstract}

Keywords: Agaonidae, Hymenoptera, Moraceae, mutualism, sex allocation.

\section{RESUMO}

\section{Efeito da competição local por acasalamentos na razão sexual de vespas de figo}

Em vespas de figo, os acasalamentos ocorrem dentro da prole de uma ou poucas vespas fundadoras, no interior do figo. Posteriormente, as fêmeas acasaladas se dispersam para colonizar novos figos. Sob estas condições, machos aparentados competem entre si por acasalamentos. Vários estudos mostram que esta competição local por acasalamentos (CLA) favorece a ocorrência de uma razão sexual da prole desviada em favor das fêmeas. Estudando Pegoscapus tonduzi que poliniza Ficus citrifolia no Brasil, nós analisamos o efeito da CLA (número de fundadoras) na razão sexual da prole das vespas polinizadoras. A relação do número de fundadoras e a razão sexual da prole seguiu qualitativamente o predito pela teoria, porém, os valores observados foram mais desviados em favor das fêmeas que o esperado. O modelo para razão sexual ótima considera que cada vespa fundadora contribui com o mesmo número de ovos na prole. A violação deste pressuposto explicaria a falta de ajuste dos resultados em relação à teoria.

Palavras-chave: Agaonidae, Hymenoptera, Moraceae, mutualismo, alocação sexual. 


\section{INTRODUCTION}

Sex allocation has motivated theoretical and empirical studies in several groups of organisms (Werren, 1980; Charnov, 1982; Frank, 1985; Herre, 1985, 1987; Martins et al., 1999; West et al., 1999, 2000a, 2000b). Fisher (1930) showed that in large, randomly mating populations, a frequency dependent selection will lead to equal parental investment in the two sexes and generally, an even sex ratio. Hamilton (1967) later pointed out that in many organisms, mating takes place among the offspring of one or a few foundress mothers in isolated subpopulations (broods) from which mated females disperse to found new broods. Under these conditions, related males will compete with each other for mating partners, local mate competition (LMC) selecting the production of female biased sex ratios. However, the same population structure that favours LMC, also leads to an increase in inbreeding levels due to mating among sibs, and thus to an increase in mother-offspring relatedness (Frank, 1985; Herre, 1985).

In haplodiploid organisms, haploid males derive all of their genome from the unfertilised eggs of a diploid mother, and thus, with inbreeding, the increase in the relatedness of mothers to daughters is relatively greater than that of mothers to sons. This asymmetry can result in female biased sex ratios independently of any effects of LMC (Herre, 1985). Assuming that foundresses contribute the same number of eggs to a brood, the optimal brood sex ratio is given by:

$p=(1-m)(2 n-1) /(4 n-1)$

where $m$ is the proportion of individuals contributed to a given brood by a single mother (reciprocal of the number of foundresses of a given brood), directly related to the LMC level; and $n$ is the harmonic mean of the number of foundresses per brood (as $n$ decreases, the overall population level of inbreeding through sib-mating increases) (Herre, 1985). Thus, sex ratios vary from $1 / 2$ (low level of inbreeding) or $1 / 3$ (high level of inbreeding) for a high number of foundresses to zero for one foundress, although realistically enough males must be produced to ensure that all females are mated (Hamilton, 1967). Pollinating fig wasps have been considered as a model system to study LMC (Hamilton, 1979; Frank, 1985; Herre, 1985,
1987; West \& Herre, 1998), although theoretical assumptions of knowledge of others ovipositing and of equal foundress contributions to broods may be violated (Kathuria et al., 1999; Kinoshita et al., 2002; Moore et al., 2002).

In this paper, we analysed the effect of LMC (number of foundresses) on the sex ratio of the offspring of fig wasps, Pegoscapus tonduzi, which pollinates Ficus citrifolia in Brazil.

\section{Background biology}

Each species of fig is pollinated by a single, species-specific pollinating wasp (Ramírez, 1970). However, exceptions to strictly one to one specificity between figs and their pollinators may be more common than had been believed (Compton, 1990; Michaloud et al., 1996; Rasplus, 1996; Molbo et al., 2003). When the figs are receptive, mated pollen-bearing female pollinating wasps (foundresses) arrive at the tree and some of them enter the enclosed inflorescence (or fig) through a bract-lined pore known as ostiole. The foundresses then pollinate the receptive, uniovulate flowers, and probe the flowers with their ovipositors, attempting to lay eggs in the ovaries (Galil, 1977). Sex determination is haplodiploid, and thus females can control the sex of their offspring by whether or not to fertilize the egg (Cook, 1993). With few exceptions, the foundress wasps subsequently die inside the fig, and their bodies may be counted to determine the number of foundresses that potentially pollinated and laid eggs in each fig (Herre, 1996).

During the next weeks, seeds and larvae of pollinating wasps develop inside the figs. Just before the fig finally ripens, the wingless males of the pollinating wasps chew their way out of the galls in which they developed, and crawl around the interior of the fig searching for galls that contain female wasps. They chew these galls open and mate with the females, which then emerge from their galls and gather pollen, prior to leaving through a hole in the fig wall chewed by the male wasps (Galil, 1977). In addition to pollinating wasps, normally other non-pollinating wasp species are associated with fig inflorescences, which develop in flower ovaries or parasitise larvae of primary galling wasps (West \& Herre, 1994; Janzen, 1979; Bronstein, 1992; West et al., 1996). 


\section{MATERIAL AND METHODS}

Ficus citrifolia is pollinated by Pegoscapus tonduzi and associated with 14 non-pollinating species in Brazil (Pereira et al., 2000-refered as F. eximia).

In order to study the $P$. tonduzi offspring sex ratio in relation to the foundress number, 25-40 figs were sampled in eight $F$. citrifolia trees in the surroundings of the Campinas State University campus (22 $54^{\prime} \mathrm{S}, 47^{\circ} 03^{\prime} \mathrm{W}$ ), between April, 1999 and August, 2001. Figs were sampled near the wasp emergence phase, before any wasp had left the fruit. Each fig was cut open and the number of foundresses counted. Fig halves were tied with a piece of wire, individually placed in plastic flasks, and all wasps allowed to emerge before being frozen. The number and sex of each species of wasp that each fig had contained were subsequently recorded. Figs with a high proportion of males (0.5-1) were assumed to have been founded by sperm-depleted females (West et al., 1997, 1998), and like figs with a low infestation level ( $P$. tonduzi broods inferior to 30 insects) were not included in the analysis.

The relationship between the number of foundresses and observed sex ratios was graphically compared to theoretical values of these ratios (Herre, 1985). We tested the effects of 1) the crop (factor variable assigning figs collected in a season from one individual tree); 2) the number of foundresses; and 3) the P. tonduzi brood size (total number of $P$. tonduzi that had emerged) per fig on the sex ratio of $P$. tonduzi (dependent variable).
Additionally, we tested the effect of the number of foundresses (explanatory variable) on the $P$. tonduzi brood size (dependent variable). In these analyses we used multiple and simple linear models, respectively, in the S-Plus 6.1 () Insightful Co. statistical package (S-Plus, 2001). We initially analyzed the sex ratio data assuming binomially distributed errors. However, the ratio of the residual deviance to the residual degrees of freedom was around five, showing considerable overdispersion, suggesting that the assumption of binomial errors was not adequate (Crawley, 1993). Consequently, we analyzed the data assuming normal errors. Sex ratios were arcsine square root transformed (Zar, 1996). In all analyses the residuals showed no obvious patterns, and plots of the ranked residuals against the standard normal deviates were close to straight lines, supporting the assumption of normal errors.

\section{RESULTS}

In seven out of eight crops sampled, we observed 6.7 to $47.5 \%$ of figs without foundress wasps, but with pollinating wasp offspring and fig seeds (Table 1). This fact indicates that the reemergence of foundress wasps does occur after pollination and egg deposition.

The sex ratio of $P$. tonduzi broods was female biased in all crops sampled (means ranging from 0.07 to 0.18 - Table 1 ). The numbers of foundresses and non-pollinating wasp offspring were quite variable both among crops and within crops

\section{TABLE 1}

Characteristics of the F. citrifolia crops sampled in Campinas/SP. Each tree code is followed by the percentage of pollinated figs without foundress wasps (the presence of seeds and pollinating wasp offspring indicated that mother wasps had successfully visited these figs) and the average \pm standard deviation of brood sex ratio, foundress number and number of fig wasps developing per figs (pollinating males and females, and non-pollinating wasps). $\mathrm{N}$ = sample size for all columns, except "\% of figs without foundresses" which shows the sample size between brackets.

\begin{tabular}{|l|c|c|c|c|c|c|c|}
\hline Tree & $\mathbf{N}$ & $\begin{array}{c}\text { \% of figs } \\
\text { without foundresses }\end{array}$ & Sex ratio & $\begin{array}{c}\text { Foundress } \\
\text { number }\end{array}$ & $\begin{array}{c}\text { Males of } \\
\boldsymbol{P} \text { tonduzi } \boldsymbol{i}\end{array}$ & $\begin{array}{c}\text { Females of } \\
\boldsymbol{P} \text { tonduzi }\end{array}$ & $\begin{array}{c}\text { Non- } \\
\text { pollinating }\end{array}$ \\
\hline BG76 & 37 & $47.5(40)$ & $0.090 \pm 0.047$ & $0.70 \pm 0.81$ & $22.1 \pm 12.8$ & $215.2 \pm 53.8$ & $21.7 \pm 24.1$ \\
\hline BG08 & 34 & $24.3(37)$ & $0.068 \pm 0.031$ & $1.53 \pm 1.38$ & $21.1 \pm 15.8$ & $264.8 \pm 72.3$ & $1.5 \pm 4.6$ \\
\hline BG87 & 25 & $28.0(25)$ & $0.090 \pm 0.033$ & $1.24 \pm 1.01$ & $19.8 \pm 9.4$ & $193.5 \pm 30.4$ & $6.0 \pm 12.1$ \\
\hline BG88 & 22 & $7.3(55)$ & $0.129 \pm 0.081$ & $4.30 \pm 3.21$ & $26.2 \pm 15.2$ & $182.5 \pm 65.4$ & $20.3 \pm 20.1$ \\
\hline BG89 & 24 & $4.0(25)$ & $0.126 \pm 0.061$ & $3.04 \pm 1.37$ & $33.7 \pm 20.4$ & $221.1 \pm 47.0$ & $7.1 \pm 10.7$ \\
\hline BG97 & 24 & $24.0(25)$ & $0.067 \pm 0.033$ & $1.17 \pm 1.01$ & $12.1 \pm 9.3$ & $158.1 \pm 53.8$ & $17.1 \pm 16.5$ \\
\hline BG98 & 19 & $6.7(30)$ & $0.162 \pm 0.085$ & $3.89 \pm 2.02$ & $35.0 \pm 26.4$ & $170.0 \pm 59.5$ & $26.5 \pm 22.4$ \\
\hline IAC & 25 & $0(25)$ & $0.180 \pm 0.072$ & $5.16 \pm 2.95$ & $56.7 \pm 26.7$ & $253.5 \pm 48.7$ & $11.7 \pm 13.7$ \\
\hline
\end{tabular}


(standard deviation usually of the same magnitude as the mean - Table 1).

Approximately $63 \%$ of the figs were founded by at least two female wasps and one foundress was the most commonly observed value (Fig. 1). The P. tonduzi progeny sex ratio was positively correlated with foundress numbers (Table 2). However, the empirical values were more female biased than theoretically predicted, even when considering the lower limit for high levels of inbreeding (Fig. 2). The divergence between empirical and theoretical values is even more significant when foundress re-emergence is taken into account, since the quantified number of foundresses might be underestimated and thus associated with higher values of sex ratio (Table 1).
The $P$. tonduzi sex ratio was positively correlated with brood size, but this relationship was weaker than the correlation between the sex ratio and the number of foundresses (Table 2).

The average $P$. tonduzi brood size observed in figs with zero or one foundress was around 200 wasps. Considering the range of one to five foundresses, each increase of one foundress produced broods seven to $13 \%$ larger than the previous one, suggesting that a single foundress is able to almost saturate a brood (Table 3 ). This trend was also shown by a weak positive correlation observed between the $P$. tonduzi brood size and the number of foundresses (slope $=11.02, t=5.31$, prob. $<10^{-4}, \mathrm{R}^{2}=0.119, \mathrm{~N}=210$ figs - Fig. 3 ).

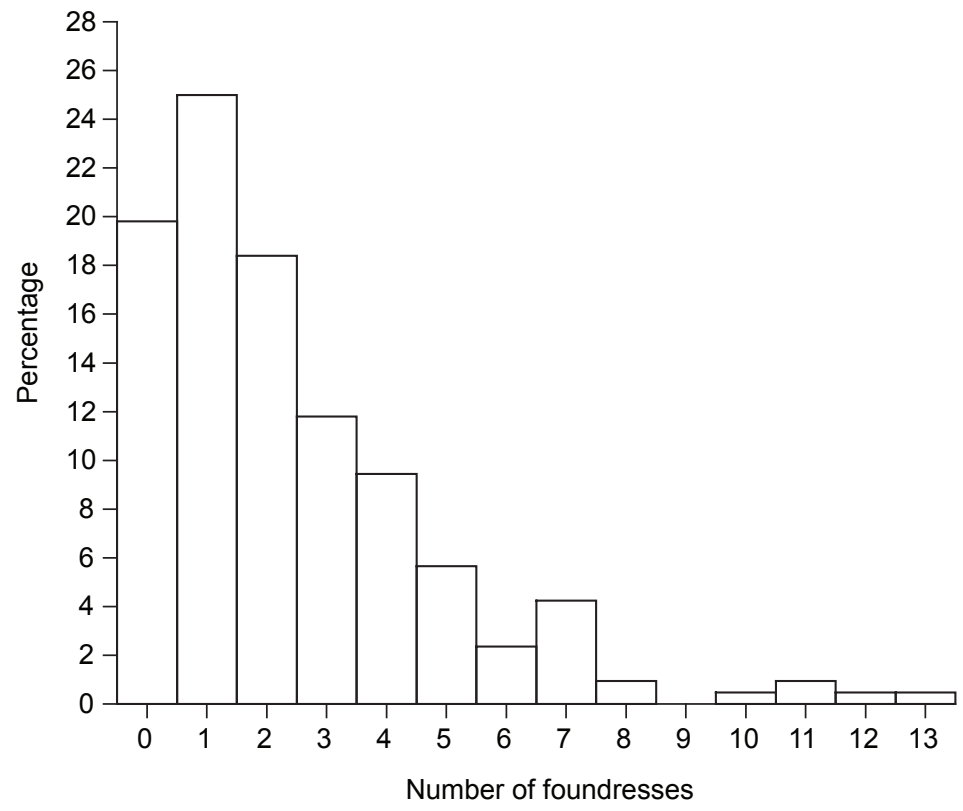

Fig. 1 - Percentage distribution of the foundress numbers in 210 figs of F. citrifolia.

TABLE 2

Linear model of the arcsine of the square root of Pegoscapus tonduzi brood sex ratio (dependent variable) vs. number of foundresses and $P$. tonduzi brood size per fig (explanatory variables). Crop was included as co-variate and its variation was significant in the model $\left(F_{7}=6.37\right.$; prob. $\left.<10^{-4}\right)$. Model statistics: adjusted $R^{2}=0.561 ; F_{9,200}=30.64 ;$ prob. $<10^{-4} ; \mathrm{N}=210$ figs.

\begin{tabular}{|l|c|c|c|}
\hline Effect & $\begin{array}{c}\text { Standardized } \\
\text { Coefficient }\end{array}$ & $\boldsymbol{t}$ & Prob. \\
\hline Constant & 0.000 & 13.523 & $<10^{-4}$ \\
\hline Foundress number & 0.548 & 8.296 & $<10^{-4}$ \\
\hline Brood size & 0.128 & 2.151 & 0.0327 \\
\hline
\end{tabular}




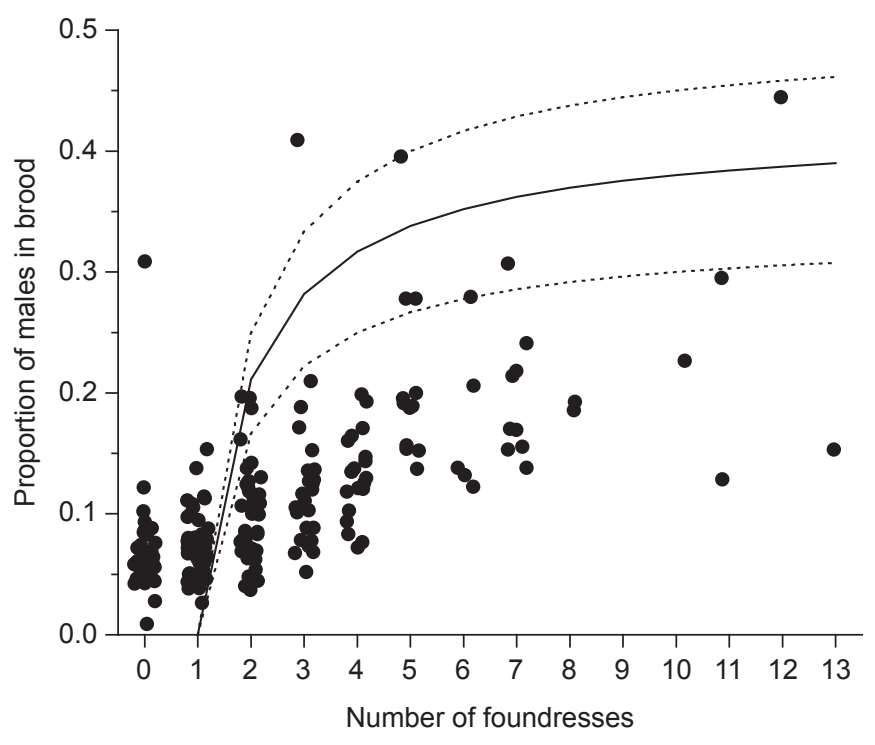

Fig. 2 - Pegoscapus tonduzi brood sex ratio as a function of foundress numbers on eight crops of $F$. citrifolia. The foundress values were jittered in order to improve visualisation. The solid line is the optimal sex ratio predicted for haplodiploid organisms at the observed LMC and inbreeding levels. Dotted lines: lower ones for high levels of inbreeding (one foundress) and upper ones for low levels of inbreeding ( $+\infty$ foundresses), according to Herre (1985) (see "Introduction").

\section{DISCUSSION}

The occurrence of figs showing pollinating wasp broods and seeds, but no inside dead foundress wasps, demonstrates that foundress reemergence following pollination/egg deposition occurred. Such re-emergence had been observed in others Ficus species (Gibernau et al., 1996; Moore et al., 2003), presenting values similar to or higher than those observed here. Foundress re-emergence leads to underestimation of the number of female wasps that actually colonised the fig. This fact had not been observed in previous studies on fig wasp sex ratios (e.g., Hamilton, 1979; Herre, 1985; 1987; 1989). Thus, when re-emergence is frequent it may interfere with analyses by adding imprecision to the association of foundress numbers and progeny sex ratios.

In observational data as presented here, it is difficult to quantify re-emergence levels, since it is only observed for colonised figs free of dead foundress wasps. In cases of higher numbers of foundresses, the re-emergence of some wasps can pass unnoticed. Increasing sample sizes do not solve this problem, but may produce more robust results, mainly if samples with low levels of re-emergence occur, such as BG89 and IAC crops (Table 1). However, molecular analyses of pollinator offspring can be used to confirm counts of foundress numbers (Molbo et al., 2002).

Our data showed that the proportion of males in $P$. tonduzi broods rose with the number of foundresses per fig, as noted in the literature (Frank, 1985; Herre, 1985, 1987; Kinoshita et al., 1998). This relationship qualitatively followed the theory (Frank, 1985; Herre, 1985; 1987), however the empirical sex ratio was more female-biased than the theoretical values, as noted in other examples (Kinoshita et al., 1998). The model for an optimal sex ratio presented by Herre (1985) considers that each foundress wasp contributes the same number of eggs to the brood. Our results suggest that this assumption does not hold in P. tonduzi. We observed that each increase of one foundress produced broods seven to $13 \%$ larger than the previous one. If sequential oviposition takes place, as reported in the literature (Kinoshita et al., 2002; Moore et al., 2002), the second foundress probably contributes with a smaller proportion of eggs to the total brood. The weak adjustment between the number of foundresses and total brood size $\left(\mathrm{R}^{2}=0.1\right.$, Fig. 3) is compatible with the suggestion that a single foundress is able to almost saturate a brood. Under 
TABLE 3

Pegoscapus tonduzi brood sizes and total number (pollinating + non-pollinating) of wasps (mean \pm SD) observed in fig with different number of foundresses. $\mathrm{N}=$ number of sampled figs. \% of change corresponds to the variation of the brood sizes by the increase of one foundress.

\begin{tabular}{|c|c|c|c|c|}
\hline Number of foundresses & $\mathbf{N}$ & $\boldsymbol{P .}$ tonduzi $\boldsymbol{i}$ brood size & \% of change & Total number of wasps \\
\hline 0 & 41 & $211.7 \pm 65.9$ & - & $226.5 \pm 67.2$ \\
\hline 1 & 53 & $207.0 \pm 58.2$ & -2.2 & $218.7 \pm 59.2$ \\
\hline 2 & 38 & $234.2 \pm 65.6$ & 13.1 & $252.5 \pm 61.6$ \\
\hline 3 & 25 & $258.7 \pm 76.0$ & 10.5 & $272.0 \pm 70.9$ \\
\hline 4 & 20 & $286.8 \pm 85.5$ & 10.8 & $297.6 \pm 76.3$ \\
\hline 5 & 12 & $307.6 \pm 65.7$ & 7.3 & $316.2 \pm 63.2$ \\
\hline 6 & 5 & $235.8 \pm 42.0$ & -23.3 & $242.8 \pm 44.7$ \\
\hline 7 & 9 & $321.7 \pm 90.9$ & 36.4 & $334.7 \pm 80.9$ \\
\hline 8 & 2 & $214.5 \pm 31.8$ & -33.3 & $228.0 \pm 29.7$ \\
\hline 10 & 1 & 384.0 & 79.0 & 394.0 \\
\hline 11 & 2 & $207.5 \pm 51.6$ & -46.0 & $221.5 \pm 53.0$ \\
\hline 12 & 1 & 117.0 & -43.6 & 150.0 \\
\hline 13 & 1 & 411.0 & 251.3 & 411.0 \\
\hline
\end{tabular}

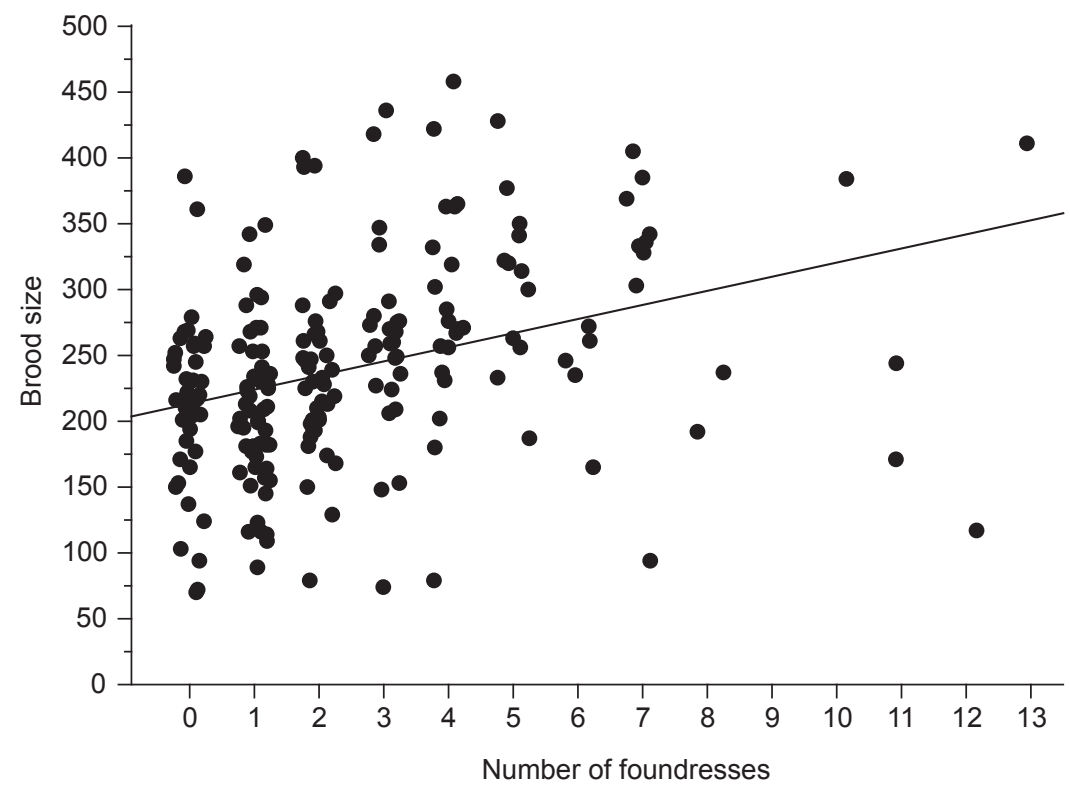

Fig. 3 - Pegoscapus tonduzi brood sizes according to foundress numbers on eight crops of $F$. citrifolia. The foundress values were jittered in order to improve visualisation. The solid line represents the linear fit (brood size $=212.6+11.0 \times$ foundress number; $\mathrm{R}^{2}=0.12$ ).

such a condition, first-arriving foundresses laid large female-biased clutches, contributing to more female-biased sex ratios. If $P$. tonduzi behaves like other fig wasp species [e.g., Liporrhopalum tentacularis (Moore et al., 2002) and Blastophaga nipponica (Kinoshita et al., 2002)], foundresses that arrive later will lay small less female-biased clutches, by facultatively adjusting their brood sex ratios according to the LMC level or by laying the males at the start of an oviposition bout (Kinoshita 
et al., 2002; Moore et al., 2002). The positive correlation between the $P$. tonduzi sex ratio and the brood size supports this hypothesis.

Recent studies have shown that the assumption of equal contribution may not always hold in some fig wasp species. Kathuria et al. (1999) showed in $F$. drupacea that per capita, foundress contribution to the brood was imbalanced and that, for situations of multiple foundresses, some of them do not contribute or lay a low numbers of eggs. In $B$. nipponica, Kinoshita et al. (2002) showed that a longer interval from entry of the first foundress to the second resulted in a smaller clutch size of second foundresses and in a more female-biased total sex ratio. Moore et al. (2002) observed that L. tentacularis females are able to oviposit sequentially and that the second foundress to arrive adjusts its sex ratio in response to the previous oviposition. Platyscapa awekei foundresses defend oviposition sites and larger females in two-foundress figs prevent smaller foundresses from ovipositing by holding them in their mandibles while ovipositing themselves. As a consequence, they lay the same number of eggs as when ovipositing in isolation, while smaller foundresses lay around $30 \%$ less eggs (Moore \& Greeff, 2003). Molbo et al. (2003), using nuclear microsatellite markers, found that in nearly $78 \%$ of the figs founded by more than one wasp, the brood belonged to only one mother. Furthermore, they could improve the adjustment of observed sex ratios to the theory using the number of foundresses that actually contributed to offspring based on genetic data rather than using the number of dead foundresses inside the figs. Unequal contributions are likely to lead to an underestimate of both, intensity of LMC and level of inbreeding. These two factors would result in the selection of more female biased sex ratios than predicted by the basic model (Frank, 1985; Herre et al., 1997; 2001). Moreover, empirical data from B. nipponica (Kinoshita et al., 2002) and Nasonia vitripennis (Flanagan et al., 1998) support the conclusion that the sex ratio of the offspring laid by a female became more strongly female biased according to the greater proportion of the total offspring laid on the patch.

Another explanation, not excluding the previous one, is that the lack of adjustment of the observed sex ratio to the theory may also be related to differences between the foundress number observed locally and the selective regime frequently found by the pollinating species. Herre (1987) observed that the lack of adjustment to the theoretical model was not at random, and that the empirical sex ratios fitted the theory better in situations (number of foundresses) more frequently found by the species. In F. citrifolia, the mean numbers of foundresses were very variable among crops (Table 1), contrasting with the high frequency of the low number of foundresses (zero and one Fig. 1). This contrast would mean that the number of foundresses occurring in some crops of $F$. citrifolia could be higher than the selective regime usually experienced by the pollinating species, explaining in part the higher female biased sex ratio found. It is important to note that the trees sampled were growing in an urban area that could be modifying original habitat conditions of both plants and pollinating wasps.

Our results reinforce the conclusion that some assumptions of traditional theoretical models are not a precisely realistic representation of natural systems (Kathuria et al., 1999; Kinoshita et al., 2002; Moore et al., 2002). Improved knowledge of the natural history of the Ficus-fig wasp system tends to reduce its importance as a valid LMC model, leading, at first to a disappointment relative to earlier discoveries. However, a useful lesson may be to change the concept of an ideal model system to a more complex system, pointing towards numerous possibilities for future studies.

Acknowledgments - We thank A. M. Rothschild for the English revision. The manuscript was greatly improved by comments from Allen Herre, Finn Kjellberg and Stuart West. R. A. S. Pereira was supported by Fapesp (studentship no: 98/05067-4) and he developed this study at Curso de Pós-Graduação em Ecologia, IB/Unicamp.

\section{REFERENCES}

BRONSTEIN, J. L., 1992, Seed predator as mutualists: Ecology and evolution of the fig pollinator interaction, pp. 1-43. In: E. Bernays (ed.), Insect-Plant Interaction, CRC Press, Boca Raton.

CHARNOV, E. L., 1982, The Theory of Sex Allocation. Princeton University Press, Princeton.

COMPTON, S. G., 1990, A collapse of host specificity in some African fig wasps. South Afr. J. Sci., 86: 39-40.

COOK, J. M., 1993, Sex determination in the Hymenoptera: a review of models and evidence. Heredity, 71: 421-435.

CRAWLEY, M. J., 1993, GLIM for ecologists. Blackwell Scientific, Oxford.

FISHER, R. A., 1930, The Genetical Theory of Natural Selection. Dover, New York. 
FLANAGAN, K. E., WEST, S. A. \& GODFRAY, H. J., 1998, Local mate competition, variable fecundity and information use in a parasitoid. Anim. Behav., 56: 191-198.

FRANK, S. A., 1985, Hierarchical selection theory and sex ratios. II. On applying the theory, and a test with fig wasps. Evolution, 39: 949-964.

GALIL, J., 1977, Fig biology. Endeavour, 1: 52-56.

GIBERNAU, M., HOSSAERT-MCKEY, M., ANSTETT, M. C. \& KJELLBERG, F., 1996, Consequences of protecting flowers in a fig: A one-way trip for pollinators? J. Biogeogr., 23: 425-432.

HAMILTON, W. D., 1967, Extraordinary sex ratios. Science, 156: 477-488.

HAMILTON, W. D., 1979, Wingless and fighting males in fig wasps and other insects, pp. 167-220. In: M. S. Blum \& N. A. Blum (eds.), Sexual Selection and Reproductive Competition in Insects, Academic Press, London.

HERRE, E. A., 1985, Sex ratio adjustment in fig wasps. Science, 288: 896-898.

HERRE, E. A., 1987, Optimality plasticity and selective regime in fig wasp sex ratios. Nature, 329: 627-629.

HERRE, E. A., 1989, Coevolution of reproductive characteristic in 12 species of New World fig and their pollinator wasps. Experientia, 45: 637-647.

HERRE, E. A., 1996, An overview of studies on a community of Panamanian figs. J. Biogeogr., 23: 593-607.

HERRE, E. A., MACHADO, C. A. \& WEST, S. A., 2001, Selective regime and fig wasp sex ratios: towards sorting rigor from pseudo-rigor in tests of adaptation, pp. 191-218. In: S. Orzack (ed.), Adaptationism and Optimality, Cambridge University Press, New York.

HERRE, E. A., WEST, S. A., COOK, J. M., COMPTON, S. G. \& KJELLBERG, F., 1997, Fig-associated wasps: pollinators and parasites, sex-ratio adjustment and male polymorphism, population structure and its consequences, pp. 226-239. In: J. C. Choe \& B. J. Crespi (eds.), The Evolution of Mating Systems in Insects and Arachnids, Cambridge University Press, Cambridge.

JANZEN, D. H., 1979, How to be a fig. Ann. Rev. Ecol. Syst., 10: 13-51.

KATHURIA, P., GREEFF, J. M., COMPTON, S. G. \& GANESHAIAH, K. N., 1999, What fig wasp sex ratios may or not tell us about sex allocation strategies. Oikos, 87: 520-530.

KINOSHITA, M., KASUYA, E. \& YAHARA, T., 1998, More highly female-biased sex ratio in the fig wasp, Blastophaga nipponica Grandi (Agaonidae). Res. Pop. Ecol., 40: 239-242.

KINOSHITA, M., KASUYA, E. \& YAHARA, T., 2002, Effects of time-dependent competition for oviposition sites on clutch sizes and offspring sex ratios in a fig wasp. Oikos, 96: 31-35.

MARTINS, R. P., ANTONINI, Y., SILVEIRA, F. A. \& WEST, S. A., 1999, Seasonal variation in the sex allocation of a neotropical solitary bee. Behav. Ecol., 10: 401-408.

MICHALOUD, G., CARRIERE, S. \& KOBBI, M., 1996, Exceptions to the one: one relationship between African fig trees and their fig wasp pollinators: Possible evolutionary scenarios. J. Biogeogr., 23: 513-520.
MOLBO, D., KRIEGER, M. J. B., HERRE, E. A. \& KELLER, L., 2002, Species-diagnostic microsatellite loci for the fig wasp genus Pegoscapus. Mol. Ecol. Notes, 2: 440-442.

MOLBO, D., MACHADO, C. A., SEVENSTER, J. A., KELLER, L. \& HERRE, E. A., 2003, Cryptic species of fig-pollinating wasps: Implications for the evolution of the fig-wasp mutualism, sex allocation, and precision of adaptation. PNAS, 100: 5867-5872.

MOORE, J. C. \& GREEFF, J. M., 2003, Resource defence in female pollinating fig wasps: two's a contest, three's a crowd. Anim. Behav., 66: 1101-1107.

MOORE, J. N., COMPTON, S. G., HATCHER, M. J. \& DUNN, A. M., 2002, Quantitative tests of sex ratio models in a pollinating fig wasp. Anim. Behav., 64: 23-32.

MOORE, J. C., DUNN, A. M., COMPTON, S. G. \& HATCHER, M. J., 2003, Foundress re-emergence and fig permeability in fig tree-wasp mutualisms. J. Evol. Biol., 16: 1186-1195.

PEREIRA, R. A. S., SEMIR, J. \& MENEZES Jr, A. O., 2000, Pollination and other biotic interactions in figs of Ficus eximia Schott (Moraceae). Braz. J. Bot., 23: 217-224.

RAMÍREZ B., W., 1970, Host specificity of fig wasps (Agaonidae). Evolution, 24: 680-691.

RASPLUS, J. Y., 1996, The one-to-one species specificity of the Ficus-Agaoninae mutualism: how casual? pp. 639-649. In: L. J. G. van der Maesen (ed.), The Biodiversity of African Plants, Kluwer Academic Publishers, Dordrecht.

S-PLUS., 2001, S-PLUS 6 for Windows User's Guide. Insightful Corporation, Seattle.

WERREN, J. H., 1980, Sex ratio adaptations to local mate competition in a parasitic wasp. Science, 208: 1157-1159.

WEST, S. A. \& HERRE, E. A., 1994, The ecology of the New World fig-parasitizing wasps Idarnes and implications for the evolution of the fig-pollinator mutualism. Proc. R. Soc. Lond. B Biol. Sci., 258: 67-72.

WEST, S. A. \& HERRE, E. A., 1998, Stabilizing selection and variance in fig wasp sex ratios. Evolution, 52: 475-485.

WEST, S. A., HERRE, E. A., WINDSOR, D. M. \& GREEN, P. R. S., 1996, The ecology and evolution of the New World non-pollinating fig wasp communities. J. Biogeogr. 23: 447-458.

WEST, S. A., COMPTON, S. G., VINCENT, S. L., HERRE, E. A. \& COOK, J. M., 1998, Virginity in haplodiploid populations: a comparison of estimation methods. Ecol. Entomol., 23: 207-210.

WEST, S. A., FLANAGAN, K. E. \& GODFRAY, H. C. J., 1999, Sex allocation and clutch size in parasitoid wasps that produce single-sex broods. Anim. Behav., 57: 265-275.

WEST, S. A., HERRE, E. A., COMPTON, S. G., GODFRAY, H. C. J. \& Cook, J. M., 1997, A comparative study of virginity in fig wasps. Anim. Behav., 54: 437-450.

WEST, S. A., HERRE, E. A. \& SHELDON, B. C., 2000a, The benefits of allocating sex. Science, 290: 288-290.

WEST, S. A., SMITH, T. G. \& READ, A. F., 2000b, Sex allocation and population structure in apicomplexan (protozoa) parasites. Proc. R. Soc. Lond. B. Biol. Sci., 267: 257-263.

ZAR, J. H., 1996, Biostatistical analysis. Prentice Hall, Upper Saddle River. 